www.mdpi.com/journal/applsci

\title{
Communication
}

\section{Properties of Thermosets Derived from Chemically Modified Triglycerides and Bio-Based Comonomers}

\section{Evan S. Beach ${ }^{1}$, Zheng Cui ${ }^{1}$, Paul T. Anastas ${ }^{1, *}$, Mingjiang Zhan ${ }^{2}$ and Richard P. Wool ${ }^{2, *}$}

1 Center for Green Chemistry and Green Engineering, Yale University, 225 Prospect St, New Haven, CT 06520-8107, USA; E-Mails: evan.beach@yale.edu (E.S.B.); greenchemistry@yale.edu (Z.C.)

2 Center for Composite Materials and Department of Chemical and Biomolecular Engineering, University of Delaware, Newark, DE 19716-3144, USA; E-Mail: zhan@udel.edu

* Authors to whom correspondence should be addressed; E-Mails: paul.anastas@yale.edu (P.T.A.); wool@udel.edu (R.P.W.); Tel.: +1-203-432-5215 (P.T.A.); Fax: +1-203-436-8574 (P.T.A.); Tel.: +1-302-831-3312 (R.P.W.); Fax: +1-302-831-8525 (R.P.W.).

Received: 30 September 2013; in revised form: 11 November 2013 / Accepted: 20 November 2013 / Published: 4 December 2013

\begin{abstract}
A series of materials was prepared by curing acrylated epoxidized soybean oil (AESO) and dibutyl itaconate (DBI) or ethyl cinnamate (EC) comonomers to provide examples of thermosets with a high proportion of bio-based carbon, in accordance with the principles of green chemistry. The comonomers, representative of cellulose-derived (DBI) or potentially lignin-derived (EC) raw materials, were tested at levels of $25 \%, 33 \%$, and $50 \%$ by mass and the resulting products were characterized by infrared spectroscopy, thermogravimetric analysis, and dynamic mechanical analysis. Both DBI and EC were incorporated into the thermosets to a high extent $(>90 \%)$ at all concentrations tested. The AESO-DBI and AESO-EC blends showed substantial degradation at $390-400{ }^{\circ} \mathrm{C}$, similar to pure AESO. Glass transition temperatures decreased as comonomer content increased; the highest $T_{\mathrm{g}}$ of $41.4{ }^{\circ} \mathrm{C}$ was observed for AESO-EC (3:1) and the lowest $T_{\mathrm{g}}$ of $1.4{ }^{\circ} \mathrm{C}$ was observed for AESO-DBI (1:1). Accordingly, at $30{ }^{\circ} \mathrm{C}$ the storage modulus values were highest for AESO-EC (3:1, 37.0 MPa) and lowest for AESO-DBI (1:1, 1.5 MPa).
\end{abstract}

Keywords: thermoset; polymer; bio-based; green chemistry 


\section{Introduction}

The reactivity of olefins found in natural oils has been widely exploited as a means of preparing novel polymers with a high proportion of the carbon derived from renewable resources. Besides well-known drying oil technologies [1], various chemical modifications of triglycerides have been explored in order to improve reactivity and access a wider range of materials with desirable properties and functional performance. One strategy has been to apply catalytic isomerization to increase conjugation of polyunsaturated fatty chains. For example Larock et al. have developed a Rh-catalyzed process that yields raw materials that are well suited for free radical and ring-opening metathesis polymerizations [2,3]. Unsaturated fatty chains may also be converted to epoxides, which may be used in curing chemistries directly or further modified with reactive maleic or acrylic functionality [4]. The latter, in the form of acrylated epoxidized soybean oil (AESO, representative structure shown in Figure 1A) has been extensively developed as the foundation for a range of bio-based polymer and composite materials: AESO has been copolymerized with numerous petroleum-derived monomers such as alkyl acrylates and methacrylates, vinyl alcohol, vinyl acetate, acrylic acid, and styrene, in thermosetting reactions promoted by free radical initiators. The resulting materials vary widely depending on the blending ratios, cure cycles, and properties of the comonomer [5]. The 12 Principles of Green Chemistry call for use of renewable resources whenever practicable [6,7], therefore recent work has focused on maximizing the bio-based content in triglyceride-derived polymer systems. Prospective biorefinery products from carbohydrates [8,9] and lignin [10] are interesting as potential feedstocks for further development of AESO chemistry. For example, Wool et al. have shown that lignin model compounds with reactive functionality can provide similar properties and functional performance as styrene in thermosetting systems [11,12]. Rosin acids have also been explored as potential alternatives to styrene or divinylbenzene [13].

Figure 1. (A) Representative structure of acrylated epoxidized soybean oil (AESO); (B) dibutyl itaconate; (C) ethyl cinnamate.

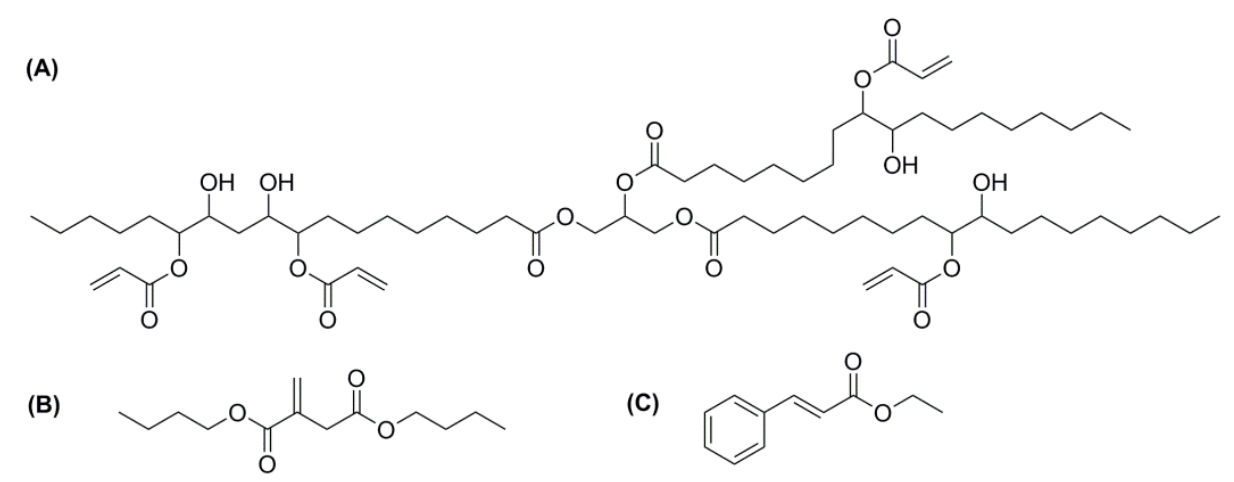

In this study, we polymerized AESO with bio-based comonomers to produce novel thermoset materials. Dibutyl itaconate (Figure 1B) was selected as one of the comonomers due to its structural similarity to acrylates and methacrylates, lower toxicity, and the status of itaconic acid as one of the US DOE "Top 10" chemical opportunities from biomass [9]. As itaconic acid is readily derived from carbohydrates via fungal fermentation, it has been successfully used in a variety of polymer applications [14]. These include as a dienophile for Diels-Alder chemistry in modification of fatty 
acids [15], grafting of polyitaconic acid onto other polymers [16], and incorporation into epoxy resins [17]. We also studied ethyl cinnamate (Figure 1C) as a lignin model compound, to determine whether the cinnamyl moieties found in native or isolated lignins (and potentially in bio-oils as well) are reactive with AESO. Dibutyl itaconate and ethyl cinnamate were incorporated into thermoset materials with AESO at various ratios and we report the resulting spectral, thermal, and mechanical properties.

\section{Experimental Section}

\subsection{General}

Acrylated epoxidized soybean oil was purchased from Sigma-Aldrich (St. Louis, MO, USA) (3.4 acrylate groups per triglyceride, average molecular weight approx. $1200 \mathrm{~g} / \mathrm{mol}$ ). Dibutyl itaconate $(>95 \%)$ was purchased from TCI America (Portland, OR, USA). Ethyl cinnamate (>98\%) and tert-butyl peroxybenzoate (98\%) was purchased from Alfa Aesar (Ward Hill, MA, USA). All chemicals were used as received. Gel permeation chromatography was performed using a Shimadzu Prominence Series HPLC (LC-20AD) system (Columbia, MD, USA) with column oven (CTO-20A) and refractive index detector (RID-10A) both maintained at $40{ }^{\circ} \mathrm{C}$. Two Phenogel columns (Phenomenex, Torrance, CA, USA; $5 \mu \mathrm{m}, 300 \times 7.8 \mathrm{~mm}$ ) were placed in series, one with $50 \AA$ and one with $100 \AA$ pore size. The system was calibrated with polystyrene standards purchased from Sigma-Aldrich (St. Louis, MO, USA). Chromatography was performed with injections on a $200 \mu \mathrm{L}$ sample loop and $1 \mathrm{~mL} / \mathrm{min}$ flow rate of tetrahydrofuran (Fisher Chemical, HPLC grade, Waltham, MA, USA). Infrared spectra were recorded using a Nicolet 6700 FT-IR spectrometer equipped with a diamond ATR accessory (Thermo Scientific, Waltham, MA, USA). Spectra were acquired in the range $500-4000 \mathrm{~cm}^{-1}$. Thermal analysis on pre-extracted samples (see Section 2.4 below) was performed with a Q500 thermogravimetric analyzer (TA Instruments, New Castle, DE, USA). The TGA samples were pre-dried in a vacuum oven at $45{ }^{\circ} \mathrm{C}$ for $24 \mathrm{~h}$, and further exposed to a stream of dry $\mathrm{N}_{2}$ gas at $50{ }^{\circ} \mathrm{C}$ for $1 \mathrm{~h}$ prior to analysis $\left(50-700{ }^{\circ} \mathrm{C}, 10^{\circ} \mathrm{C} / \mathrm{min}\right)$. Mechanical and viscoelastic properties were characterized with a Q800 dynamic mechanical analyzer (TA Instruments, New Castle, DE, USA).

\subsection{Synthesis of Homopolymers}

Poly(dibutyl itaconate) was prepared and purified based on a previously published procedure, which was modified to use $t$-butylperoxybenzoate as the initiator [18]. Similarly, poly(ethyl cinnamate) was prepared and purified according to the literature but using the $t$-butylperoxybenzoate initiator [19].

\subsection{Representative Procedure for Copolymerization of the Bio-Based Resins}

AESO and comonomer in the desired ratio, with $t$-butyl peroxybenzoate initiator $(2 \mathrm{wt} . \%$ of the total mixture) were mechanically blended for at least $5 \mathrm{~min}$ using an overhead stirrer. To prevent oxygen free radical inhibition, the mixture was then purged with nitrogen gas for 5 min and placed under vacuum to remove gas bubbles. The purge/vacuum cycle was repeated 3 times. The resin was then poured into a silicone mold between two steel plates and cured by the application of heat. The curing process for all resins was $90{ }^{\circ} \mathrm{C}$ for $2 \mathrm{~h}$ with postcure at $120{ }^{\circ} \mathrm{C}$ for $2 \mathrm{~h}$ based on previously 
demonstrated conditions for curing of AESO resins [20,21]. The polymer samples were allowed to cool to room temperature and were polished with fine sandpaper prior to further analysis.

\subsection{Determination of Extractable Content in the Bio-Based Resins}

Samples (1 g) were fragmented and extracted overnight in $15 \mathrm{~mL}$ dichloromethane. The insoluble material was placed in a dessicator under continuous vacuum for a further $24 \mathrm{~h}$ prior to weighing.

\section{Results and Discussion}

\subsection{Degree of Incorporation of Bio-Based Monomers}

Thermosets were prepared with AESO-DBI or AESO-EC mixtures with mass ratios of 3:1, 2:1, and 1:1 (for clarity, samples will be discussed according to these mass ratios unless otherwise noted). The corresponding molar ratios of reactive functionalities are 2.1:1, 1.4:1, and $0.7: 1$ for the DBI series and $1.5: 1,1.0: 1$, and $0.5: 1$, comparable to previous studies of comonomer blends. Initiator and thermal curing cycles were similarly based on earlier studies of AESO reactivity [5,20,21]. Extraction with dichloromethane gave $>99 \%$ recovery of insoluble material for the AESO-DBI series. For the AESO-EC series, $>99 \%$ recovery was obtained for the $3: 1$ blend but was $95 \%$ for the $2: 1$ ratio and $90 \%$ for the 1:1 ratio. Further exploration of initiator and curing conditions would be necessary to improve the incorporation levels of EC. The mass recovery observations were in good agreement with infrared spectroscopic analysis.

\subsection{Infrared Spectroscopy}

Infrared spectra were measured for each of the AESO-DBI and AESO-EC mixtures. A representative spectrum for AESO-DBI (1:1) is shown in Figure 2; the spectrum was not significantly different at lower levels of DBI. Pure AESO has a $\mathrm{C}=\mathrm{C}$ stretch at $1635 \mathrm{~cm}^{-1}$, and pure $\mathrm{DBI}$ has a $\mathrm{C}=\mathrm{C}$ stretch at $1642 \mathrm{~cm}^{-1}$; neither of these is apparent in the spectrum of the copolymer, indicating high degree of polymerization of the $\mathrm{C}=\mathrm{C}$ functionality. The broad, strong $\mathrm{C}=\mathrm{O}$ stretching frequencies centered around $1729 \mathrm{~cm}^{-1}$ are apparent, characteristic of fatty ester functionality in the triglyceride backbone as well as acrylate and itaconate ester moieties. Corresponding $\mathrm{C}-\mathrm{O}$ stretches are observed at 1162 and $1062 \mathrm{~cm}^{-1}$.

Figure 2. Infrared spectrum of AESO-DBI (1:1) thermoset.

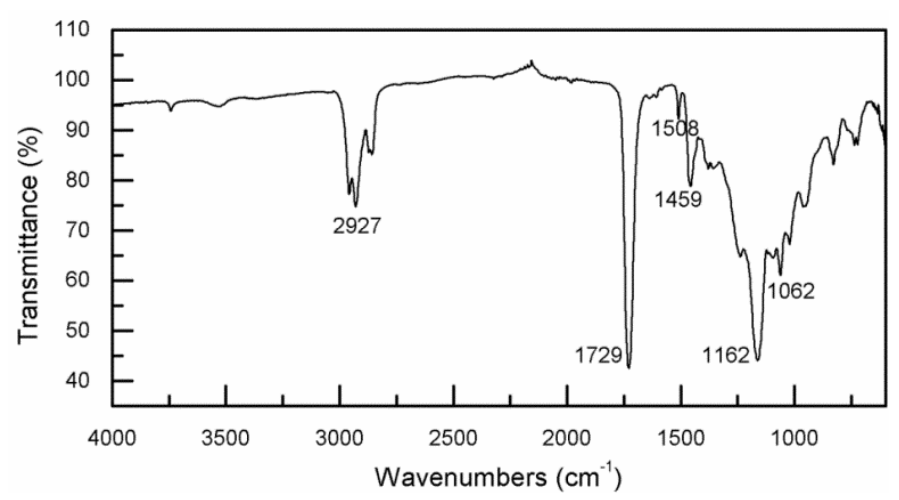


In contrast, the AESO-EC spectra showed evidence of unreacted starting material. Pure EC has a $\mathrm{C}=\mathrm{C}$ stretch at $1639 \mathrm{~cm}^{-1}$ and the copolymer shows a distinct peak at $1637 \mathrm{~cm}^{-1}$ (Figure 3). Peaks seen at 981 and $836 \mathrm{~cm}^{-1}$ are also consistent with pure EC. Other signals are consistent with polymerized AESO as discussed above.

Figure 3. Infrared spectrum of AESO-EC (1:1) thermoset.

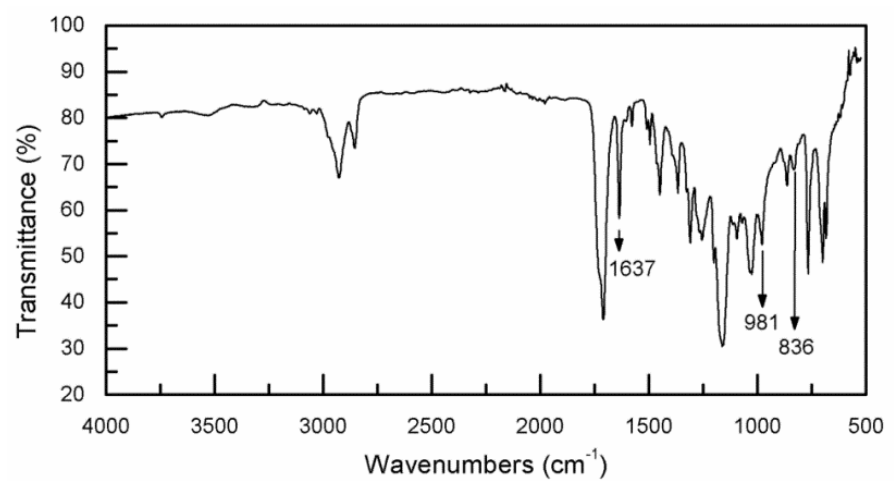

\subsection{Thermal Stability}

The thermal stability of the polymers was studied by thermogravimetric analysis (TGA). Results for DBI homopolymer and AESO-DBI thermosets are shown in Figure 4, and T5, T10, T50, and char yield values are shown in Table 1.

Figure 4. Thermogravimetric curves for poly(DBI) and AESO-DBI thermosets. Black traces correspond to mass loss vs. temperature; gray traces are the corresponding derivative plots.

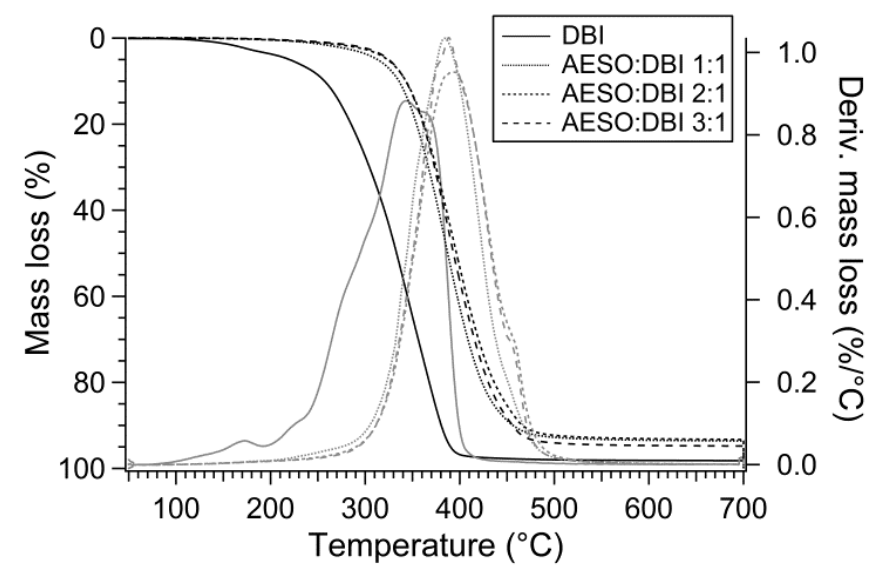

Table 1. Thermogravimetric data for DBI and EC homopolymers, AESO-DBI, and AESO-EC resins. T5, $T 10$, and $T 50$ temperatures correspond to mass loss of $5 \%, 10 \%$, and $50 \%$ respectively. Char yield is based on residue at $700{ }^{\circ} \mathrm{C}$.

\begin{tabular}{ccccc}
\hline Sample & $\mathbf{T 5}\left({ }^{\circ} \mathbf{C}\right)$ & $\mathbf{T 1 0}\left({ }^{\circ} \mathbf{C}\right)$ & $\mathbf{T 5 0}\left({ }^{\circ} \mathbf{C}\right)$ & Char yield \\
\hline DBI homopolymer & 220 & 257 & 333 & $1.74 \%$ \\
AESO:DBI 1:1 & 313 & 336 & 387 & $6.34 \%$ \\
AESO:DBI 2:1 & 324 & 343 & 397 & $6.66 \%$ \\
\hline
\end{tabular}


Table 1. Cont.

\begin{tabular}{ccccc}
\hline Sample & $\mathbf{T 5}\left({ }^{\circ} \mathbf{C}\right)$ & $\mathbf{T 1 0}\left({ }^{\circ} \mathbf{C}\right)$ & T50 $\left({ }^{\circ} \mathbf{C}\right)$ & Char yield \\
\hline AESO:DBI 3:1 & 325 & 343 & 393 & $5.16 \%$ \\
EC homopolymer & 233 & 296 & 352 & $0.53 \%$ \\
AESO:EC 1:1 & 309 & 337 & 390 & $2.86 \%$ \\
AESO:EC 2:1 & 318 & 344 & 398 & $2.42 \%$ \\
AESO:EC 3:1 & 326 & 348 & 402 & $2.84 \%$ \\
\hline
\end{tabular}

For the AESO-DBI blends, the TGA data show that the major degradation process has an onset around $300{ }^{\circ} \mathrm{C}$, and the maximum rate of degradation occurs at $385-390{ }^{\circ} \mathrm{C}$, apparently independent of the DBI content. The $T 50$ values are very similar to that of pure AESO thermoset $\left(398^{\circ} \mathrm{C}\right)$ [13], for which the major thermal transformation is decomposition of the crosslinked polymer network and random scission of the linear chains [22]. In the case of DBI homopolymer, the sample shows loss of mass in the $150-200{ }^{\circ} \mathrm{C}$ range. GPC data showed that the purified DBI homopolymer still contained residual DBI monomer $(<5 \%)$, therefore we attribute the lower-temperature mass loss to the monomer, which was not present in the AESO resins.

EC homopolymer (Figure 5) showed two major degradation stages centered at $153{ }^{\circ} \mathrm{C}$ and $355{ }^{\circ} \mathrm{C}$. TGA of EC monomer showed sharp mass loss centered at $165^{\circ} \mathrm{C}$; therefore it is likely that the EC homopolymer contained a small amount of unreacted EC. The AESO-EC samples show that unreacted EC was removed by the solvent extraction pre-treatment. Consumption of EC via thermal $[2+2]$ dimerization during the cure was not expected due to the higher temperatures $\left(>200{ }^{\circ} \mathrm{C}\right)$ that would be required [23]. T5, T10, and $T 50$ values for the two series of thermosets are comparable. The values for AESO-EC are slightly higher than those for the DBI series, suggesting that the aromatic content in EC may provide limited stability, but in general the T50 values are not significantly different than the T50 of AESO alone. Char values are low for all materials tested, in agreement with the literature on thermal stability of AESO and AESO blends [13].

Figure 5. Thermogravimetric curves for poly(EC) and AESO-EC thermosets.

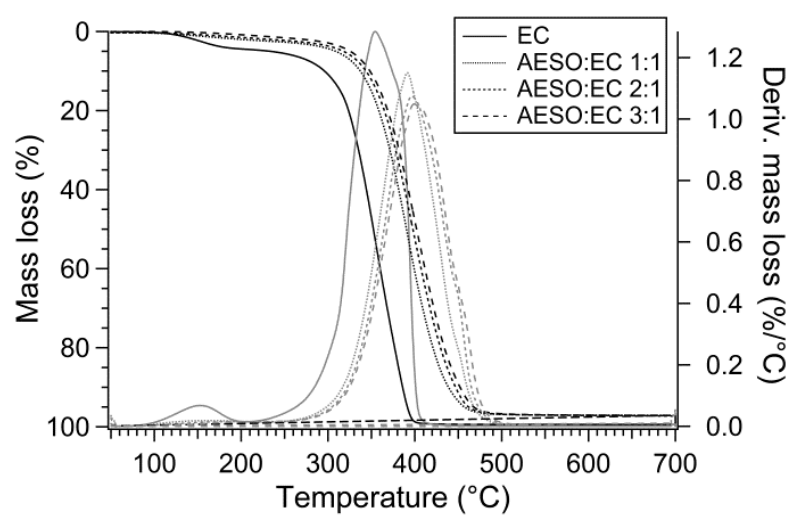

The AESO blends were further characterized by dynamic mechanical analysis (DMA). Representative traces of storage modulus as a function of temperature for AESO-EC blends are shown in Figure 6. Tan $\delta$ curves as a function of temperature (Figures 7 and 8 ) were used to determine $T_{\mathrm{g}}$ for AESO-DBI and AESO-EC materials. The results are summarized in Table 2. 
Figure 6. Storage modulus as a function of temperature for AESO-EC thermosets.

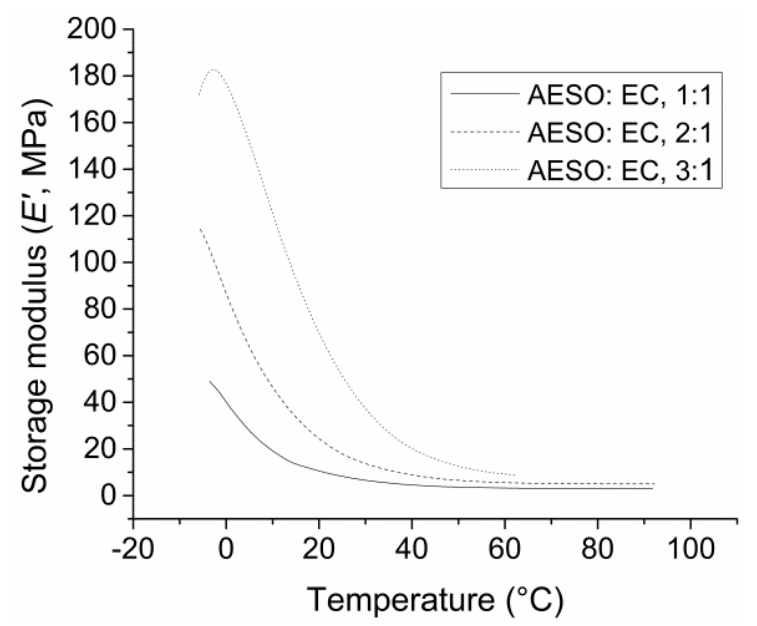

Figure 7. Tan $\delta$ as a function of temperature for AESO-DBI thermosets.

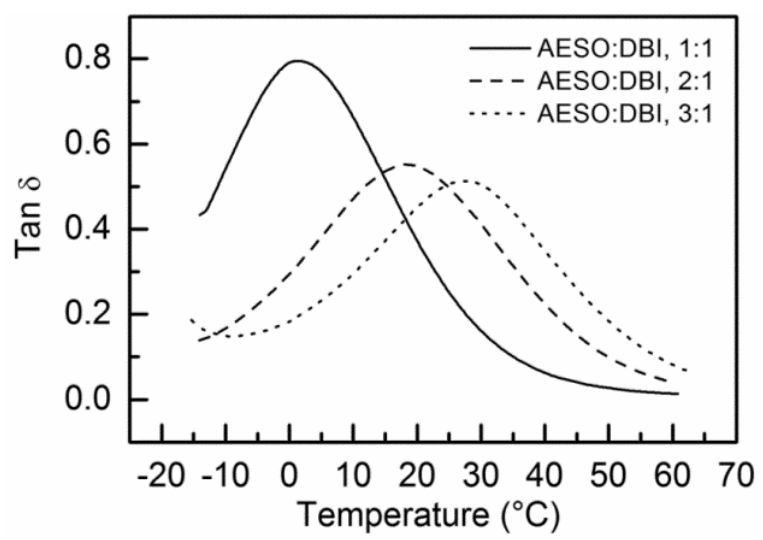

Figure 8. Tan $\delta$ as a function of temperature for AESO-EC thermosets.

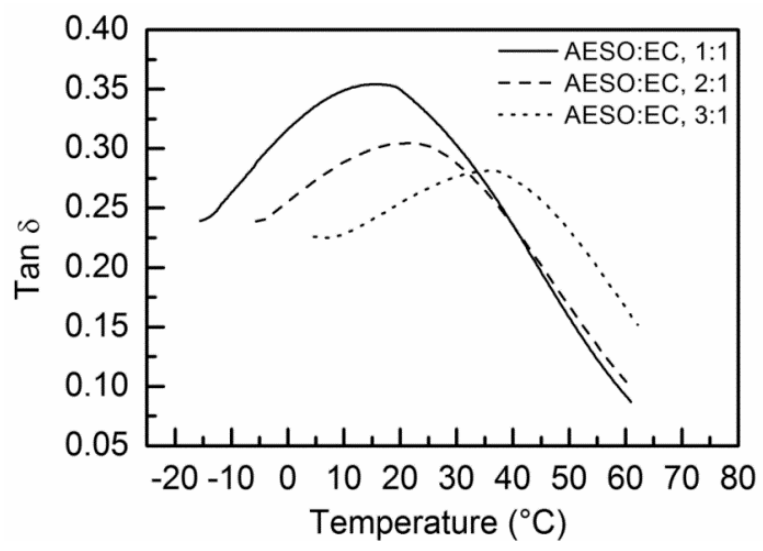

Table 2. Glass transition and viscoelastic properties of AESO blends (Each measurement was made on two different samples).

\begin{tabular}{ccccccc}
\hline Sample & AESO: EC, 1:1 & AESO: EC, 2:1 & AESO: EC, 3:1 & AESO: DBI, 1:1 & AESO: DBI, 2:1 & AESO: DBI, 3:1 \\
\hline $\begin{array}{c}\left.T_{\mathrm{g}} \text { (as Tan } \delta \text { peak, }{ }^{\circ} \mathrm{C}\right) \\
\begin{array}{c}\text { Storage modulus E } \\
\left(\text { at } 30{ }^{\circ} \mathrm{C}, \mathrm{MPa}\right)\end{array}\end{array}$ & $14.2,15.6$ & $21.0,21.1$ & $41.4,36.3$ & $1.4,2.5$ & $18.4,19.2$ & $27.3,25.4$ \\
\hline
\end{tabular}


The $T_{\mathrm{g}}$ of AESO homopolymer depends on the degree of acrylation; a typical value is about $47^{\circ} \mathrm{C}$ [5]. In this study, lower values were observed as the amount of EC or DBI increases; this can be attributed to lower cross-link density as both DBI and EC can only serve as linear chain extenders. The $T_{\mathrm{g}}$ of DBI homopolymer is $14.7^{\circ} \mathrm{C}$ [24]. Since we observe $T_{\mathrm{g}}$ values as low as $1-2{ }^{\circ} \mathrm{C}$ for AESO-DBI polymers, lower than the $T_{\mathrm{g}}$ of DBI or AESO homopolymers, the copolymer shows a strong plasticizing effect. Interestingly, this is the opposite of the effect reported in an AESO-methyl methacrylate system [25]. In the case of the 1:1 AESO-EC blend, the presence of unreacted liquid EC is likely reducing the glass transition temperature. However, in all cases the observed $T_{\mathrm{g}}$ values are slightly higher than those seen for the AESO-DBI blends, suggesting that the aromatic content of the copolymer provides some rigidity. The experimental results are in good agreement with the Twinkling Fractal Theory of the glass transition, which has been extensively used to model the properties of polymers based on acrylated oils [26,27].

Storage modulus (E') values for both AESO-DBI and AESO-EC samples were substantially lower than that of pure AESO which is about $320 \mathrm{MPa}$ at $30^{\circ} \mathrm{C}$. This is consistent with the rubbery nature of the materials which are above or near the glass transition point at room temperature. The modulus values decrease with decreasing AESO content due to the lower crosslink density. In other studies of AESO blends, decreased E' values have been seen for comonomers such as methacrylated lauric acid $\left(100 \mathrm{MPa}\right.$ at $\left.30{ }^{\circ} \mathrm{C}\right)$, whereas styrene blends provide significant increases (typically $>1 \mathrm{GPa}$ at $30{ }^{\circ} \mathrm{C}$ ) [21]. Based on the known properties of related thermoset systems, triglyceride-based copolymers with DBI and EC could be obtained with higher $T_{\mathrm{g}}$ and modulus values through two strategies. First, increasing crosslink density could be achieved by working with starting oils having a higher degree of unsaturation (for example, linseed oil), leading to a higher proportion of reactive acrylate groups after derivatization. Crosslink density can also be increased through maleic anhydride modification of residual $\mathrm{OH}$ groups, so the resulting monomers (MAESO) have additional reactive sites [5]. Second, incorporation of fibers into AESO-based resins is known to improve mechanical performance. Renewable resources such as keratin, chicken feathers, and sisal have been recently reported for such a purpose [28-30].

\section{Conclusions}

We have shown that DBI and EC can be copolymerized with AESO to produce thermoset materials. DBI is readily incorporated into the polymer matrix with AESO at levels of $25 \%-50 \%$ by mass. The glass transition temperature decreases rapidly with increasing amounts of DBI, decreasing below even the $T_{\mathrm{g}}$ for DBI homopolymer. Under the cure conditions investigated, unreacted EC was detected when the starting blend was $33 \%-50 \%$ EC by mass, although it is apparent that the major portion of the added EC did react with AESO. The thermal behavior of the systems are similar to poly(AESO) but the storage modulus is much lower, suggesting that alternative approaches such as fiber reinforcement might be necessary to provide performance comparable to petroleum-derived comonomer systems. Our findings suggest that itaconic acid, as a promising biomass platform chemical, may be interesting as a potential replacement for petroleum-based acrylates in AESO-comonomer systems. Also, since we have demonstrated that the cinnamate functionality is reactive, lignin-derived bio-oils containing high 
levels of cinnamate functionality may similarly be useful in thermosets. Altogether, this suggests directions for future development of bio-based thermoset systems based on modified triglycerides.

\section{Conflicts of Interest}

The authors declare no conflict of interest.

\section{References}

1. Zoebelein, H. Dictionary of Renewable Resources, 2nd ed.; Wiley-VCH: Weinheim, Germany, 2001.

2. Quirino, R.L.; Larock, R.C. Bioplastics, Biocomposites, and Biocoatings from Natural Oils. In Renewable and Sustainable Polymers; American Chemical Society: Washington, DC, USA, 2011; Volume 1063, pp. 37-59.

3. Xia, Y.; Quirino, R.L.; Larock, R.C. Bio-based thermosetting polymers from vegetable oils. J. Renew. Mat. 2013, 1, 3-27.

4. Khot, S.N.; La Scala, J.J.; Can, E.; Morye, S.S.; Williams, G.I.; Palmese, G.R.; Kusefoglu, S.H.; Wool, R.P. Development and application of triglyceride-based polymers and composites. J. Appl. Polym. Sci. 2001, 82, 703-723.

5. Wool, R.P.; Sun, X.S. Bio-Based Polymers and Composites; Elsevier Academic Press: Boston, MA, USA, 2005.

6. Anastas, P.T. The transformative innovations needed by green chemistry for sustainability. ChemSusChem 2009, 2, 391-392.

7. Beach, E.S.; Cui, Z.; Anastas, P.T. Green chemistry: A design framework for sustainability. Energ. Environ. Sci. 2009, 2, 1038-1049.

8. Werpy, T.; Petersen, G. Top Value Added Chemicals from Biomass, Volume I: Results of Screening for Potential Candidates from Sugars and Synthetic Gas; US Department of Energy: Oak Ridge, TN, USA, 2004.

9. Bozell, J.J.; Petersen, G.R. Technology development for the production of biobased products from biorefinery carbohydrates - The US Department of Energy's "Top 10" revisited. Green Chem. 2010, 12, 539 .

10. Holladay, J.E.; White, J.F.; Bozell, J.J.; Johnson, D. Top Value Added Chemicals from Biomass, Volume II: Results of Screening for Potential Candidates from Biorefinery Lignin; US Department of Energy: Oak Ridge, TN, USA, 2007.

11. Stanzione, J.F.; Giangiulio, P.A.; Sadler, J.M.; La Scala, J.J.; Wool, R.P. Lignin-based bio-oil mimic as biobased resin for composite applications. ACS Sustain. Chem. Eng. 2013, 1, 419-426.

12. Stanzione, J.F.; Sadler, J.M.; La Scala, J.J.; Wool, R.P. Lignin model compounds as bio-based reactive diluents for liquid molding resins. ChemSusChem 2012, 5, 1291-1297.

13. Ma, Q.; Liu, X.; Zhang, R.; Zhu, J.; Jiang, Y. Synthesis and properties of full bio-based thermosetting resins from rosin acid and soybean oil: The role of rosin acid derivatives. Green Chem. 2013, 15, 1300.

14. Willke, T.; Vorlop, K.D. Biotechnological production of itaconic acid. Appl. Microbiol. Biotechnol. 2001, 56, 289-295. 
15. Sastry, G.S.R.; Murthy, B.G.K.; Aggarwal, J.S. Diels-Alder adducts of safflower oil fatty acids. Itaconic acid as a dienophile. Farbe und Lack 1972, 78, 927-929.

16. Sugama, T.; Cook, M. Poly(itaconic acid)-modified chitosan coatings for mitigating corrosion of aluminum substrates. Prog. Org. Coat. 2000, 38, 79-87.

17. Ma, S.; Liu, X.; Jiang, Y.; Tang, Z.; Zhang, C.; Zhu, J. Bio-based epoxy resin from itaconic acid and its thermosets cured with anhydride and comonomers. Green Chem. 2013, 15, 245-254.

18. Cowie, J.M.G.; Henshall, S.A.E.; McEwen, I.J.; Velickovic, J. Poly(alkyl itaconates). 4. Glass and sub-glass transitions in the di-alkyl ester series, methyl to hexyl. Polymer 1977, 18, 612-616.

19. Marvel, C.S.; McCain, G.H. Polymerization of esters of cinnamic acid. J. Am. Chem. Soc. 1953, $75,3272-3273$.

20. La Scala, J.; Wool, R.P. Rheology of chemically modified triglycerides. J. Appl. Polym. Sci. 2005, 95, 774-783.

21. Campanella, A.; La Scala, J.J.; Wool, R.P. Fatty acid-based comonomers as styrene replacements in soybean and castor oil-based thermosetting polymers. J. Appl. Polym. Sci. 2011, 119, $1000-1010$.

22. Lu, J.; Wool, R.P. Novel thermosetting resins for smc applications from linseed oil: Synthesis, characterization, and properties. J. Appl. Polym. Sci. 2006, 99, 2481-2488.

23. Sung, S.-J.; Cho, K.-Y.; Hah, H.; Lee, S.; Park, J.-K. Effect of plasticization of poly(vinyl cinnamate) on liquid crystal orientation stability. Jpn. J. Appl. Phys. 2005, 44, L412-L415.

24. Fernández-García, M.; Madruga, E.L. Glass transitions in dimethyl and di- $n$-butyl poly(itaconate ester)s and their copolymers with methyl methacrylate. Polymer 1997, 38, 1367-1371.

25. La Scala, J. The Effects of Triglyceride Structure on the Properties of Plant Oil-Based Resins, Vol. 1. Ph.D. Thesis, University of Delaware, Newark, DE, USA, 2002.

26. La Scala, J.; Wool, R.P. Fundamental thermo-mechanical property modeling of triglyceride-based thermosetting resins. J. Appl. Polym. Sci. 2013, 127, 1812-1826.

27. Wool, R.P. Twinkling fractal theory of the glass transition. J. Polym. Sci. B 2008, 46, 2765-2778.

28. Hong, C.K.; Wool, R.P. Development of a bio-based composite material from soybean oil and keratin fibers. J. Appl. Polym. Sci. 2005, 95, 1524-1538.

29. Senoz, E.; Stanzione, J.F.; Reno, K.H.; Wool, R.P.; Miller, M.E.N. Pyrolyzed chicken feather fibers for biobased composite reinforcement. J. Appl. Polym. Sci. 2013, 128, 983-989.

30. Lee, K.-Y.; Ho, K.K.C.; Schlufter, K.; Bismarck, A. Hierarchical composites reinforced with robust short sisal fibre preforms utilising bacterial cellulose as binder. Compos. Sci. Technol. 2012, 72, 1479-1486.

(C) 2013 by the authors; licensee MDPI, Basel, Switzerland. This article is an open access article distributed under the terms and conditions of the Creative Commons Attribution license (http://creativecommons.org/licenses/by/3.0/). 